\title{
Artificial Intelligence Approach to Creative Data Manipulation for Optimisation of Livelihood Oriented Urban Planning and Management
}

\author{
Jiafeng Zhou ${ }^{\mathrm{a}}$, Tian Liu ${ }^{\mathrm{b}, *}$, and Lin Zou ${ }^{\mathrm{c}}$ \\ ${ }^{a}$ Creative Centre for Arts-Science-Architecture (CCASA), Jilin Jianzhu University, Jilin, 130118, China \\ ${ }^{b}$ School of Tourism and Foreign Languages, Henan Institute of Economics and Trade, Zhengzhou, 450000, China \\ ${ }^{c}$ Centre for Creative Computing, Bath Spa University, Bath, LE1 7RH, England, UK
}

\begin{abstract}
Livelihood oriented urban planning management (LOUPM), which holds that all economic and political activities center on human development, involves many aspects like the object, subject, system, and its aim. This paper aims to address the optimisation of LOUPM aspects through creative computing. Software systems will be engineered to help achieve optimised solutions in urban planning and management. By involving artificial intelligence, the proposed controller is engineered to output related data, which will be re-inputs of edited results into the system. This paper raises a way to improve the context-aware ability of the controller through a data manipulation tool that enhances the self-adaptive software to solve both certain and uncertain problems especially in livelihood oriented planning and management. The controller employs control theory-based modules and combination-based modules to generate outputs more than activities with costs or balanced scorecards. In this process, Livelihood Orientation (LO) context sensors are added. The controller with LO sensors relies heavily on the extraction and filtering of LO data collected and should be capable of reacting to environment changes. Thus, this controller enables the self-adaptive software to know users' needs precisely. Not only can the preset parameters be changed, but also the self-adaptivity is able to modify parameters. This creative approach is economical, effective, and efficient in LOUPM.
\end{abstract}

Keywords: livelihood oriented urban planning and management; game theory; natural language processing; artificial intelligence; creative computing

(Submitted on November 15, 2018; Revised on December 20, 2018; Accepted on January 17, 2019)

(C) 2019 Totem Publisher, Inc. All rights reserved.

\section{Introduction}

Creative computing endeavors to offer creativity in interdisciplinary fields with creative software engineering. One way to achieve creativity is believed to combine knowledge from seemingly different areas, so much knowledge other than computing is invited into computing [1]. Hence, a creative data manipulation Tool is raised in LOUPM. This paper justifies this contribution with its framework and explains it in detail. Instead of the user command, the data manipulation tool emphasizes other elements. Control theory obeys strict logic in performance, and in order to change the traditional control process, it can be combined with game theory. This combination is creative.

LOUPM aims to optimise the aspects of livelihood and satisfy the needs of human development, with its emphasis on the urban functions of livelihood and its focus on social justice and humans' real needs [1]. It also holds that the ultimate goal of government management is to fulfil people's living and development.

Software needs certain operations when tackling scattered applications in a changing environment. During the operation, the open-loop structures embedded in software makes the maintenance time-consuming. Aiming to be simple, efficient, effective, and automatic, the self-adaptive software with artificial intelligence is suggested to meet demands.

This paper discusses the data collection for optimisation of livelihood oriented urban planning and management.

\footnotetext{
* Corresponding author.

E-mail address: 307344323@qq.com, liutianbeth@qq.com, Lin.zou14@bathspa.ac.uk
} 


\section{Foundation Research}

\subsection{The Definition and Characteristic of LOUPM}

LOUPM is closely related to the residents' broad participation [2]. Democratic participation guarantees livelihood as a necessary system [3]. LOUPM democracy is the state of power designating the rules, forms, and procedures in planning task establishment, task entrusting, plan establishment, evaluation, approving, implementation, management, adjusting, etc. It includes the democratic methods in urban planning (UP), the democratic style in UP management and decision making, the democratic forms in UP legislation, etc. Democratisation in UPA is a basic tendency in modern UP. With the constant urbanisation, the urban development raises more requirements and needs more residents' participation. Only through the orderly broadening of citizens' political participation can more social advice be gathered, and consequently the government will better understand and consider the needs of the society in UP decision making and implementation. Meanwhile, broad resident participation has many advantages, like arousing the residents' participation interests in UP, resulting in greater strength in urban construction. Democratic participation and supervision can better improve LOUPM. The development of livelihood political construction can result in not only the good willingness of officials and the government but also democratic participation, which is the fundamental promoting force.

From the perspective of the subjects of management, LOUPM raises an appropriate method to deal with economic growth and livelihood improvement through the clarification of the limits and scope of livelihood politics. Without economic growth, livelihood cannot be guaranteed. Livelihood orientation does not weaken the economic development function of UP but rather realises a positive interaction between economic growth and livelihood optimisation through reasonable and effective resource allocation [4].

Livelihood orientation regards as its ultimate goal the realisation of humans' value, rights, and liberties, and it constructs the LOUPM system to improve life quality, boost the development potential, and increase the happiness index. It has the following three features [5]. First, LOUPM reflects livelihood politics, promotes humans' living conditions, and realises humans' dignity and value. Thus, two basic goals are set in urban planning and construction: one is to promote the city's development, while the other is to better guarantee public interest and improve humans' living conditions. Both coexist with each other in that only through the promotion of the city's development economically and socially can livelihood be better realized, and an improved livelihood is not only the goal of urban planning and construction but also a key guarantee of the city's long and positive development.

Second, LOUPM adopts a system with the function of the government management guided by livelihood politics [6]. A different developing goal requires different measures, which cannot be separated from different structures and function systems. Different management systems and functions will lead to different behavior decisions. Based on different city development goals or different priorities attached to different issues, urban management offices can define their functions and build corresponding management units to cater to specific functions. First, the government, the object of urban planning and management, changes its functions to pay more attention to livelihood requirements so that the decisions and implementations by the government better reflect the gists of livelihood politics. This makes the government reform the original urban planning and management offices in order to strengthen the functions of such offices as survey, decision-making, implementation, and feedback and decrease the obstacles created by the system itself. More broad participation of multi-bodies in the society can achieve a better solution of social livelihood needs and promotes the ability of offering public products and services. Therefore, the traditional urban planning and management system needs the necessary combination with new citizen participation methods and interest expression and provides reasonable guidance to the participating bodies from the market and the society in livelihood services. Finally, a LOUPM system is established. Second, the subject of urban planning and management needs to allocate more resources to livelihood fields. Compared with the needs in the city development, resources are always relatively in a state of shortness. A key problem in UPA is how to reasonably allocate, coordinate, and integrate limited resources to promote city development and construction. Third, systems of LOUPM laws and regulations should be established and perfected to guarantee the effects. In the system establishment, not only should the object, subject, and relation in LOUPM be defined, but also corresponding laws and systems should be built to guarantee their roles in the management.

Finally, LOUPM usually occurs in the rapid growth of city modernisation [7]. Any planning and management activities cannot be separated from their outer environment. The changes in the outer environment make the important power in the promotion of government functions and administrative methods reforms. Because of the relative shortness of resources, livelihood problems can be solved with necessary resources, but the multi-dimensional and broad needs cannot be fully satisfied. Therefore, livelihood politics become a prominent problem in politics. Interest conflicts and multi-values make people's living community tense. LOUPM is an approach to solve these problems and a key measure taken in the process of 
urban government modernisation. With the necessary material foundation and the occurrence of livelihood problems, livelihood politics is needed in government decision-making.

Any planning management activity should be put in the background of a certain space and time [8]. The appropriate understanding of the urban planning management scope does good to the integration of resources and achievements of basic goals. Two scopes are involved in the basic process of UPM. The first concerns the right scopes in LOUPM, namely the right scopes of the government and bodies in the market and society, which is also a prior problem. The second concerns the scopes of time and space, including regulations on time and space about usable resources and obstacles.

\subsection{The Three Scopes of LOUPM}

\subsubsection{The Authority Scope}

There are three scopes that need to be considered for LOUPM, which are authority, space, and time.

The authority scope should be considered inside the government [9]. LOUPM requires the government to divide the authority with a priority on livelihood. It is anticipated that a development oriented government and a livelihood oriented government may raise different planning management systems in guaranteeing the planning implementation.

The first is the horizontal authority relation and system establishment inside the government. Generally speaking, the UPM system includes the systems of decision making, implementation, and evaluation. The livelihood orientation in UPM should be realised through the adjustment and perfection of those three systems, leading to the LOUPM system [10]. First, the livelihood oriented decision making system should be established. Decision making is a prior activity in UPM. A key issue in LOUPM system construction is how to emphasise livelihood problems through effective system construction and attach appropriate attention to livelihood in the procedure setting and system guarantee. Second, the livelihood oriented mechanism in the procedure setting should be perfected. This requires more voice from offices in charge of livelihood and more voice from the public in the decision making discussion. Third, a livelihood oriented think tank and suggestion mechanism should be built and perfected.

The second is the vertical authority relation adjustment inside the government. The reforms in UPM authority mainly witness three stages: centralisation, partial downward moving, and general decentralisation. Generally speaking, deepening reforms make the management authority move down to the lower government step by step. For example, in this process, the authorities of the district and town governments increase continually. The basic offices in the city government are usually closely related to the daily life of the public and have a more whole and direct understanding of the livelihood problems. Thus, more authorities concerning daily livelihood planning management should be provided to them without affecting integrative urban construction planning management of the city. The city government only has to offer more guidance, integration, and supervision so as to boost the initiative and the human feelings in the planning management of the district, street, and town. The interest differences and group forming lead to great gaps between people's needs. The city government needs to consider the public's livelihood needs as a whole and promote equalisation in the basic urban public service system. The basic level government understands more of the daily needs of the public and has the ability to fully consider the area's resources, public, and space. Area planning set by the basic government can satisfy people's daily needs. In this process, the city government needs to offer on the scale of the whole city integration, guidance, and supervision, and it provides necessary resources and money so that the urban planning management system can be established in a way that the basic government fully displays the dominant authority under the integration of the city government.

On the other hand, authority allocation happens between the government and bodies in the market and society. The complexity of urban life, separation of interests, and different needs of groups make the city government unable to fulfill the supply of public products and services on its own. With the appearance of new classes, groups, material conditions, and technologies in modern society, the requirements of people on life standards are increasing. In the modernisation of society and economy, new social classes and new job groups come into existence, and they raise new and higher requirements on the public service provided by the government. Therefore, the "expectation reform" occurs. These expectations and needs increase continuously, making the city government unable to satisfy people's livelihood needs through traditional methods. For this reason, the city government should guide and invite the bodies from the market and the society to join in the urban planning management, through which more strengths can be attracted to the livelihood construction. On the one hand, the democratic participation by multi-bodies enables the government to consider more different needs and suggestions by more people. On the other hand, in modern society, multi-bodies also make great strengths in livelihood services. Through a series of settings in the system, the government can outsource some public products and services to other bodies. This method can not only relieve the government's pressure in livelihood construction but also improve people's living 
environment and conditions. In this process, the key lies in the clarification of authority scopes between the government, market, and society and the formation of the dominant mechanism and the participation mechanism in the orderly planning construction.

\subsubsection{The Space Scope}

It is no doubt that urban planning management can only utilise resources in a limited space [11]. The management activities are limited by many aspects in the space of the city. Thus, in LOUPM activities, the city government should consider a variety of resources and disadvantages in the space, designing livelihood construction plans suitable for the real situation of the city. For example, the space of land determines the scope of urban management because the city should guarantee the land supply for economic development and livelihood based on the limited land space. Another example is that some cities endowed with certain resources need the space for the development of resources that may cause livelihood problems. Otherwise, some cities enjoy better chances in solving livelihood problems owing to better land resources.

First, the regional space defines the city's urban planning management. Some cities should not only develop individually but also bear certain regional functions. Even some central cities should be in charge of the corresponding functions of the development of the whole country. These regional functions will definitely influence the overall planning of the city. The urban planning management will certainly consider their regional functions and regional status. Due to their many functions occupying large lands in some central cities, livelihood lands will encounter shortness. On the contrary, their regional functions also to some extent offer material conditions in solving the problems in the city development and livelihood. Therefore, how to balance the region's functions, fully utilise the usable resources in the region's space, decrease space limits, achieve livelihood improvement, and promote LOUPM are what the urban planning management departments should consider.

Second, the city's resource space defines the UPM scope. In urban planning, the advantages and disadvantages of the city's resources should be considered so as to suit the planning with the city's natural conditions. Problems in UPM include how to fully utilise the city's natural and cultural resources, how to avoid the shortcomings, and how to effectively integrate all resources to promote LOUPM. Some cities lack a clear understanding of their advantages and disadvantages, comparing their shortcomings with others' strengths, and then encounter the waste of resources and the drawback of development, so the livelihood problems cannot be solved. The key to promote livelihood is to transform the natural endowments to rich materials and people's treasure. On this basis, through corresponding urban planning, resources are allocated reasonably, and livelihood is guaranteed by effective resource utilisation. In the end, people can live a quality life in an orderly urban community.

LOUPM is an unavoidable subject in future urban development. The discussion on its basic definition, features, and scopes clarifies the relations of various elements. An objective analysis and understanding of these elements help understand its management process.

\subsubsection{The Time Scope}

Any planning management has its time span. Planning management departments need to consider the reality of the area and comprehensively examine all rich and poor resources involved in the goal achievement that offer a time span. The ultimate goal of LOUPM is to make livelihood the priority in urban planning management and continually satisfy people's growing needs in material and culture. However, in this process, goals may enjoy different priorities according to their urgency and importance. Different needs should be treated in an appropriate order. This requires the UPM departments to coordinate the relation between different interest groups according to the city's comprehensive strength. Thus, the urban construction plan can satisfy the livelihood needs on different levels, and the overall schedule of LOUPM can be established.

Livelihood is of the nature of multi-goals and consists of needs on different levels. LOUPM aims to set livelihood politics as its management goal, which cannot be achieved overnight and requires orderly promotion. Generally speaking, livelihood politics includes the increase of living standards, the ability to supply public products and services, and just opportunities offered by the system and environment. The promotion of LOUPM first requires the reasonable allocation of resources and the improvement of the city environment, offers people living guarantee, and improves people's living standards. In this process, the low and middle income groups should be focused on, so that everybody can live a decent life in the city and enjoy the achievements of the opening-up and reform policy. Second, on the basis of the growing life quality, the capacity of providing public products and services should be strengthened through urban planning and construction so as to effectively connect the urban development strategies with the livelihood. The development of livelihood cannot be separated from urban development, but the only emphasis on urban development may neglect the solution of livelihood 
problems and hinder the urban development itself consequently. Therefore, on the basis of improving people's living conditions, the developing style should be altered completely with the final goal aiming at livelihood politics. Finally, the realisation of livelihood politics cannot be separated from a just society and management system. Only in a just society and management system can everyone's living and development opportunity and the right to change their fate be guaranteed. The ultimate goal of LOUPM is to establish a just political and social environment in which everyone can reasonably express ideas and pursue their happiness. These three goals are not isolated and in a linear order, but they are interwoven with each other. Due to the constraints of the reality, the livelihood construction should have escalating management goals to help realise LOUPM.

\subsection{Creativity and Knowledge Combination}

In computing, there are mainly three approaches, namely, rationalist, scientific, and technocratic. This limitation is rooted in the binary system. Strict logics should be followed in programming, which is inimical to creativity. From the rationalist perspective, computer science is even considered as a part of mathematics. On the contrary, from the technocratic perspective, software engineering is more than rigidly following logics and can be flexible with creative ideas. Based on that, creative computing goes further to add more creative elements [1].

Self-adaptive software bears little creativity due to control theory, and parameter settings are limited for the shortness of background knowledge [3]. Thus, it is significant to explore other ways to enhance creativity. One way is knowledge combination, which holds that creativity can be achieved by combining knowledge from different fields [4].

This paper is based on the knowledge combination in creative computing. Figure 1 illustrates the closed feedback loop control system. A recursive control structure is adopted. Both models are similar and can gain a synergy effect.

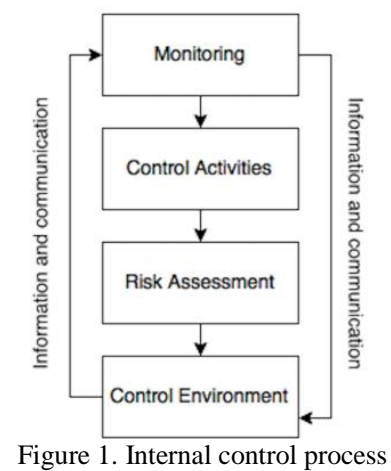

Knowledge combination can occur in the multidisciplinary, interdisciplinary, and transdisciplinary way to promote creativity. Accordingly, the two models are combined.

The control system follows logics strictly to get the output, so results cannot be flexible and changes cannot occur. It is not self-adaptive if the system cannot react to different conditions. However, conditions play a key role in information analysis. Background information, knowledge, and environment exert great influence on information processing. For example, Hamlet can be interpreted in quite different ways by people with different backgrounds. Also, knowledge in one field can inspire experts in another field, which always happens. A historian's idea may shed light on a biologist. Hence, this paper will engineer a self-adaptive system by combining control theory with game theory.

\subsection{Relevant Context-Awareness}

This paper will engineer the self-adaptive software by making control context-aware. The first step is to classify the contexts, and then context control in LOUPM will be designed. Context-awareness refers to the software being aware of the changes of the conditions. It can detect the changes and make relevant reactions so that users' needs can be anticipated beforehand and users get better computing services [5]. Although no consensus has been reached concerning its definition, it is agreed by most that context deals with the interaction of users and the system.

\subsubsection{Context Categories}

Although an agreement has not been reached concerning the context categories, much research has been conducted in 
different fields. Generally, context can be classified into four types: computing, user, physical, and time context [6].

- Computing Context: This refers to elements like network connectivity, commutation cost, and communication bandwidth. Nearby resources are also included sometimes.

- User Context: This refers to users' information like user profile, location, and social situation.

- Physical Context: This is to a large extent relevant to the traditional adaptive system. It mainly involves lighting, noise, temperature, and traffic condition. Time Context: It basically contains the time of day, week, month, and seasons of the year.

Overall, context about both the computing environment and users is of value and should be considered in the human and computer interaction.

\subsubsection{Software Context Control in LOUPM}

Concerning urban planning, some context-aware applications have already been developed, such as the context-sensitive access control model [7] and management control system [8]. They provide pioneering ideas and also leave much space for further exploration.

- The context-sensitive access control model is engineered based on the role-based access control model. Both have increasingly distinct role hierarchies [7]. Meanwhile, the context-sensitive access control model suffers from the poor quality of context information, e.g., reliability and accuracy. This paper will cater this problem with context awareness control.

- Urban planning offices often utilizes traditional systems. These include internal control and financial control. They usually include activity-based costs and a balanced scorecard and can meet offices' needs. In computer-based context control construction, major components are referred to. Figure 2 illustrates the involved parameters in the internal control process.

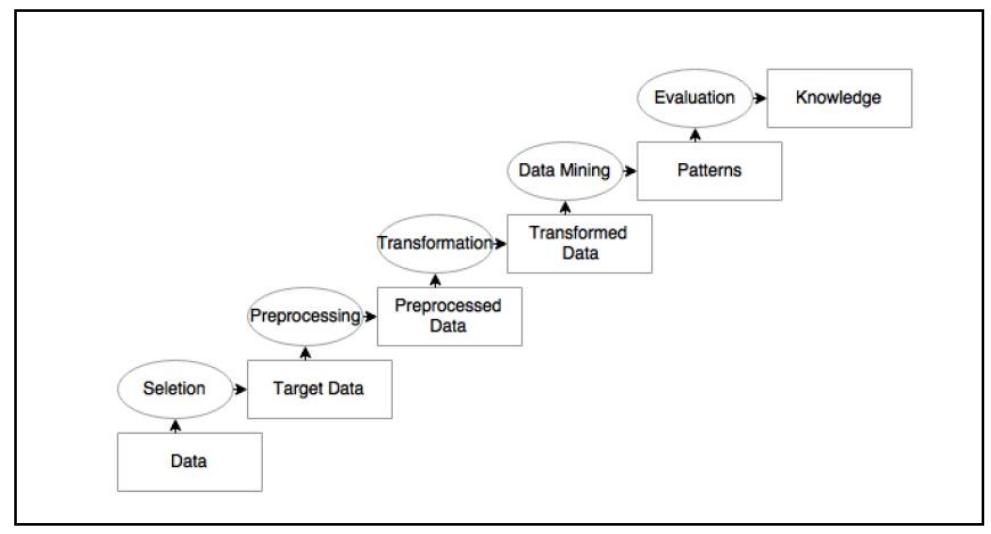

Figure 2. Data mining steps

Thus, livelihood orientation is the focus in context construction. This paper aims to extract relevant data from traditional models and parameters.

\subsection{Game Theory and Artificial Intelligence}

Game theory is an inclusive term about decision-making logic, either human or non-human [12]. This paper adopts game theory to enable software to make proper decisions so that software can be self-adaptive.

Urban planning, especially LOUPM, is a complex process that cannot be solved with logic control. Also, most of the time, game theory serves as a possible solution to help deconstruct the abstract livelihood orientation into logical rules for the system to follow. In behavioural game theory, ideas are raised to explain how humans can gain strategic decisions based on the previous experience. For example, bargaining strikes and joint activity co-ordinations are discussed [13].

Game theory has been influential in social science. It is also suitable to solve the problems in LOUPM, because it usually needs to coordinate different interests and conflicts [10]. The game theory model is even used to deal with 
bargaining and negotiations between nations [13]. Thus, it is reasonable to apply it in this paper to tackle LOUPM as a human does.

For example, the persuasion game explores asymmetric interactions. It mainly conducts security protection and key information disclosing. In practice, it fails to function due to the agency problem [14]. Later, the agency problem is solved by the zero-knowledge proof [15].

\section{Main Research Approach}

Control theory and game theory provide distinct software decisions. This paper combines them creatively to engineer the self-adaptive software to facilitate LOUPM. Recursive control is applied in closed feedback loop control. With the development of AI, software can better process much information and gain desirable decisions given proper algorithms like game theory.

Three major functions are fulfilled by closed feedback loop control. Data awaiting processing includes the three scopes of LOUPM, namely authority, space, and time.

\subsection{Self-Adaptive Framework}

In this paper, the controller will compare the results of both functions. This includes natural language understanding and machine learning-based scope detector.

\section{Stage 1: Natural Language Understanding}

Output: RDF form data

LOUPM information usually exists in the form of natural language, and it is necessary to transform it into Resource Description Framework (RDF) data so that it can be recognised by the system. LOUPM data in RDF form can be further processed by the controller. This is a key stage for data collection because it feeds the following steps.

Stage 2: Machine Learning-based Scope Detector

Input: LOUPM data in RDF form from Stage 1

Output: OWL form data including authority, time, and space information

LOUPM data are vast, so the paper will establish a data manipulation tool through machine learning. Relevant machine learning algorithms are applied to classify the three scopes of data. Training data sets about the three scopes are established, and then they are used to classify LOUPM data into the related scopes. The data will be reformed into OWL, so they can be searched in a semantic way.

In this process, the self-adaptive software can adjust parameters with or without triggering the controller. If the controller is triggered by the context, game theory will be employed.

\subsection{Nash Equilibrium Model and Recursive Context Control}

The self-adaptive ability is realized through the game theory and control process. It gains certain flexibility from game theory interwoven.

\section{Stage 1: Context Extraction}

Input: LOUPM Scope data in OWL form

Tools and Core Theory: Data mining

Output: A query database contains SWOT analysis. SWOT refers to Strength, Weakness, Opportunities, Threat.

Parallel Stage: Internal control process 
The process includes more than activity-based costs or balanced scorecards. Livelihood orientation is reflected by the involved conditions. The given aspects influence the output of the controller. The creative data manipulation lies in the flexible processing of the involved elements to suit the needs of livelihood preservation.

Stage 2: Game Theory Logical Program

Input: Extracted RDF context

Tools: Game theory models

\section{Output: Parameter order}

As mentioned above, there is an internal control process happening at the same time as the context extraction before this stage. Game theory has some typical models like Pareto optimality and Nash equilibrium. In this stage, game theory is realized with rigid logic models. During this process, variables are ranked according to the power law. Three tags of aggressive, conservative, and middle are attached to the outcome.

\subsection{Data Collection, Cleansing, and Filtering}

Data mining refers to the process of extracting knowledge and insights across disciplines. It is a major method to gain knowledge, and the data can be structured or unstructured. Also, it is an important way in Knowledge Discovery in Databases (KDD). Usually, KDD has the following steps: selection, preprocessing, transformation, data mining, and evaluation [6]. Data cleansing amends or removes data in the database that is incorrect, incomplete, improperly formatted, or duplicated. The purpose of data cleansing is to provide the ground for further processing. Data cleansing usually includes the five steps of planning, analysing to cleansing, automation implementing, appending missing data, and monitoring. Three methods are involved, including defining, searching, and correcting. Python is a flexible programming language that may tackle data from different sets directly.

- The selection step selects variables or data samples by creating the target data set and subset.

- The preprocessing step cleans data to preprocessed data.

- The transformation step reduces the effective number of variables and finds useful features to represent the data depending on the goal of the task by using dimensionality reduction or the transformation method.

- The data mining step contains several algorithms such as summarisation, classification, and regression to search the patterns of interest in transformed data.

- The evaluation step interprets mined patterns and visualises the extracted patterns and models to knowledge.

\section{Conclusions}

An appropriate understanding of the scopes of LOUPM helps to conduct this project. Mainly, the three scopes of authority, time, and space need to be clarified. The authority scope mainly refers to three relations, one between offices of different levels, one of the same level, and the other between government offices and social bodies. The time scope mainly deals with the determination of priorities and the sequence and order of tasks. The space scope provides the geographic data about the specific region and resources. The data manipulation tool asks for great context-aware ability. The paper combines the control with game theory to make the data manipulation tool flexible and process the intangible concept of livelihood orientation in LOUPM. Game theory integrates livelihood orientation scopes with control theory to achieve the expected result. It proves to be creative. A prototype will be offered later to prove the ideas in this paper.

\section{References}

1. F. Ellis, "Rural Livelihood Diversity in Developing Countries: Evidence and Policy Implications," Odi Natural Resource Perspectives, No. 40, pp. 1-10, 1999

2. N. Barter, "The Perception of the Environment: Essays on Livelihood, Dwelling and Skill," Social and Environmental Accountability, Vol. 4, No. 1, pp. 142-158, 2009

3. B. Barrett, T. Reardon, and P. Webb, "Nonfarm Income Diversification and Household Livelihood Strategies in Rural Africa: Concepts, Dynamics, and Policy Implications," Food Policy, Vol. 26, No. 4, pp. 315-331, 2001

4. M. Foster, "Cities of Tomorrow: An Intellectual History of Urban Planning and Design in the Twentieth Century, by Peter Hall," Journal of Geography, Vol. 61, No. 60, pp. 187-199, 2010

5. K. Yu, "Criticizing Urbanity and Approaching Livelihood Art of Urban Planning," Journal of Shanghai Polytechnic College of 
Urban Management, pp. 40-42, 2008

6. G. Lu, Y. Sun, and W. Wang, "Study of Urban Planning Electronic Government Affairs System," Modern Surveying \& Mapping, Vol. 27, No. 5, pp. 6-10, 2004

7. S. Willem, "Experimenting with New Urban Planning Strategies under Conditions of Radical Modernization," The Planning Review, Vol. 45, No. 176, pp. 39-46, 2009

8. K. V. Assche, "Signs in Time: An Interpretive Account of Urban Planning and Design, the People and their History," Wur Wageningen Ur, pp. 121-133, 2004

9. X. Song and X. Jian, "The Challenges of the Authority Decentralization, îÄ Discuss on Administrative Mechanism of Urban Planning in Shanghai," Urban Planning Review, Vol. 28, No. 6, pp. 14-18, 1999

10. B. Mumtaz, "A Livelihoods Approach to Urban Planning," In: B. Mumtaz, and N. Kaj, (eds.) Development of Kabul: Reconstruction and Planning Issues, pp. 141-151, Comportments: Lausanne, 2004

11. L. Zhou and S. Cui, "New Space of Urban Planning in the New Normal," City Planning Review, Vol. 40, No. 4, pp. 9-26, 2016

12. R. Chenhall, "Management Control Systems Design Within its Organizational Context: Findings from Contingency-based Research and Directions for The Future," Accounting, Organizations and Society, Vol. 28, No. 2, pp. 127-168, 2003

13. G. H. Snyder and P. Diesing, "Conflict Among Nations: Bargaining, Decision Making, and System Structure in International Crises," Princeton University Press, 2015

14. P. Horn, "Autonomic Computing: IBM's Perspective on the State of Information Technology," International Livelihood Oriented Machines Co., pp. 10-39, New York, 2001

15. A. Kelly, "Decision Making using Game Theory: An Introduction for Managers," Cambridge University Press, 2003 